\title{
HIV/AIDS mortality trends pre and post ART for 1997 - 2012 in South Africa - have we turned the tide?
}

\author{
V Pillay-van Wyk, ${ }^{1}$ MPH, PhD; W Msemburi, ${ }^{1}$ MPhil; R E Dorrington, ${ }^{2}$ BCom, BSc Hons, BA, MPhil, FASSA; \\ R Laubscher, ${ }^{3}$ B Comm (Maths); P Groenewald, ${ }^{1} \mathrm{MB}$ ChB, MPH; D Bradshaw, ${ }^{1,4}$ MSc, DPhil \\ ${ }^{1}$ Burden of Disease Research Unit, South African Medical Research Council, Cape Town, South Africa \\ ${ }^{2}$ Centre for Actuarial Research, Faculty of Commerce, University of Cape Town, South Africa \\ ${ }^{3}$ Biostatistics Unit, South African Medical Research Council, Cape Town, South Africa \\ ${ }^{4}$ School of Public Health and Family Medicine, Faculty of Health Sciences, University of Cape Town, South Africa
}

Corresponding author: V Pillay-van Wyk (victoria.pillayvanwyk@mrc.ac.za)

Background. South Africa (SA) has one of the largest HIV/AIDS epidemics in the world and the most extensive antiretroviral therapy (ART) programme globally, which was rolled out from 2004. This paper reports the trends in HIV/AIDS mortality pre and post ART rollout in SA.

Methods. Vital registration cause-of-death data from Statistics South Africa were adjusted for under-reporting of deaths using demographic methods. Misattributed HIV/AIDS deaths were identified by regressing excess mortality on a lagged indicator HIV antenatal clinic prevalence for causes found to be associated with HIV/AIDS. Background trends in the source-cause mortality rates were estimated from the trend in cause-specific mortality experienced among 75 - 84-year-olds. Mortality rates were calculated using mid-year population estimates and the World Health Organization world standard age-weights.

Results. We estimated over 3189000 HIV/AIDS deaths for 1997 - 2012. In 1997, 60336 (14.5\%) of deaths were attributed to HIV/AIDS; this number peaked in 2006 at 283564 (41.9\%) and decreased to 153661 (29.1\%) by 2012; female mortality rates peaked in 2005 and those of males in 2006. Men aged 35 years and older had higher mortality rates than did women. While the rates at ages below 65 years in 2012 were lower than those in 2006, rates of those age 65 years and older remained unchanged.

Conclusion. The number of HIV/AIDS deaths has almost halved since the ART rollout. Of concern is the high mortality in men 45 years and older and the high mortality of men compared with women in the older ages by 2012; this gap has increased with age. Treatment and prevention programmes should strategise how to target men.

S Afr Med J 2019;109(11 Suppl 1):S41-S44. https://doi.org/10.7196/SAMJ.2019.v109i11b.14283

South Africa (SA) is one of the countries worst affected by the HIV/AIDS epidemic and has the most extensive publicly provided antiretroviral therapy (ART) programmes in sub-Saharan Africa. ${ }^{[1]}$ This programme began in 2004. ${ }^{[2]}$ The Human Sciences Research Council has been conducting national HIV prevalence, incidence, behaviour and communication surveys at three-yearly intervals since 2002; consequently, national and provincial trends in prevalence, incidence and behaviour are available for the country. ${ }^{[3-6]}$ However, there are few empirical estimates of HIV/AIDS mortality at national and provincial levels for SA. Tracking trends in HIV/AIDS mortality is paramount to understanding the progress made before and after the ART programme rollout in the country. To date, this has been done through model estimates which in recent years (e.g. Thembisa) ${ }^{[7,8]}$ have calibrated the model to the total number of deaths experienced but not to cause-specific mortality.

SA has a vital registration system that routinely collects cause-ofdeath information that is processed and released by Statistics South Africa (Stats SA). Stats SA clearly states in their mortality and causes report that 'The quality of the causes of mortality statistics depends on the completeness and accuracy of the certified death notification forms. When coding causes-of-death statistics, the coders at Stats SA follow the principle of 'what you see is what you code. ${ }^{[9]}$ As a consequence, Stats SA does not adjust for misattributed HIV/AIDS deaths; this is a huge problem in SA, as medical doctors still report HIIV/AIDS deaths as due to other causes, because stigma and discrimination still exist around the disease. ${ }^{[10]}$ This trend is reflected by the low proportion of deaths reported to HIV/AIDS by Stats SA; for example, 3.8\% in 2012. ${ }^{[11]}$ As part of the second National Burden of Disease Study, led by the South African Medical Research Council (SA MRC), Bradshaw and colleagues $^{[12]}$ developed a method for identifying misattributed HIV/ AIDS deaths which were then reallocated to HIV/AIDS. The present paper reports a comprehensive analysis of HIV mortality focusing on trends by sex, age and province that formed part of the second National Burden of Disease study (NBDS 2) ${ }^{[13]}$ and assesses the impact of ART by focusing on the pre- and post-ART rollout periods. Although model estimates of the number of HIV-related deaths have indicated the impact of $\mathrm{ART},{ }^{[7,14]}$ this work provides estimates based on empirical data on the impact of ART.

\section{Methods}

The methodology used in the NBDS 2 has been well documented elsewhere. ${ }^{[12,13,15]}$ Briefly, the vital registration cause-of-death data from Stats SA for the years 1997 - 2012 were adjusted for underreporting of deaths using demographic methods. ${ }^{[1,15]}$ Kaposi's sarcoma (C46), HIV pseudonyms such as 'retroviral disease' and 'immune suppression' (B33, B45, B59 and D84) were added to the HIV/AIDS (B20 - B24) deaths. Misattributed HIV/AIDS deaths were identified by regressing excess mortality on a lagged indicator HIV antenatal clinic prevalence. ${ }^{[12]}$ Background trends in the source-cause mortality rates were estimated by extrapolating rates in 1995 (i.e. before the impact of HIV), using the trend in cause-specific mortality experienced among 75 - 84-year-olds (assumed to be largely free of AIDS deaths). ${ }^{[12}$ 
Mortality rates were calculated using midyear population estimates ${ }^{[16]}$ and the World Health Orgnization (WHO) world standard age-weights. ${ }^{[17]}$ The causes of death that were estimated to include the misattributed AIDS deaths are presented by age and sex. Changes in the number of AIDS deaths and the agespecific death rate are presented for selected years $(1997,2000,2006$ and 2012) to track the progression of AIDS mortality during the different periods of ART availability, and the provincial trends in AIDS mortality are presented to highlight the differential impact across the country.

\section{Results}

\section{Identifying AIDS deaths}

Using the methods of Bradshaw et al, ${ }^{[12]}$ over $3189000 \mathrm{HIV} /$ AIDS deaths were estimated for the period 1997 - 2012. Most of the HIV/AIDS deaths were misattributed to other conditions; $23 \%$ were misattributed to tuberculosis (TB) (i.e. $69 \%$ of reported TB deaths), 15\% to lower respiratory infections (i.e. $60 \%$ of reported lower respiratory infections deaths), $10 \%$ to diarrhoeal disease (i.e. $57 \%$ of reported diarrhoeal disease deaths) and $18 \%$ to ill-defined deaths (i.e. $38 \%$ of reported ill-defined deaths). Only $7 \%$ of all HIV/AIDS deaths were reported as HIV/AIDS. There was no significant difference in the pattern of misattributed deaths by sex within each age group except for females $15-19$ years old who had more than 3 times more AIDS deaths than males across all the categories of misattributed deaths (Figs 1a and 1b).

\section{AIDS deaths}

In 1997, $60336(14.5 \%)$ of deaths were attributed to HIV/AIDS; this number peaked in 2006 at 283564 (41.9\%) and decreased to 153661 (29.1\%) by 2012; $;^{[13]}$ female mortality rates peaked in 2005 and those of males in 2006 (data not shown).

By 2012, there was a dramatic decrease in the number of HIV/AIDS deaths in children $<1$ year of age - amounting to only one-third of the deaths compared with 1997 (Fig. 2). A less pronounced decrease occurred for children 1 - 4 years old. The numbers in other age groups did not decline to the same extent, with none yet falling to 1997 levels by 2012. The numbers of deaths in all age groups, except those $\geq 60$ years, were noticeably lower in 2012 than in 2006.

Disaggregating the analysis by sex and calculating mortality rates, which account for population size in each age and sex group, revealed interesting male-female differences (Figs $3 \mathrm{a}$ and $3 \mathrm{~b}$ ). In the 25 - 34-year age group, women had higher mortality rates than did men. This pattern reversed in the $\geq 45$ years age groups. While the rates in 2012 are lower than those in 2006 at all ages $<65$ years, and lower than those in 2000 at ages $<35$ years, there was little improvement since 2006 in the rates of those $\geq 65$ years old. None of the 9 provinces in SA had by 2012

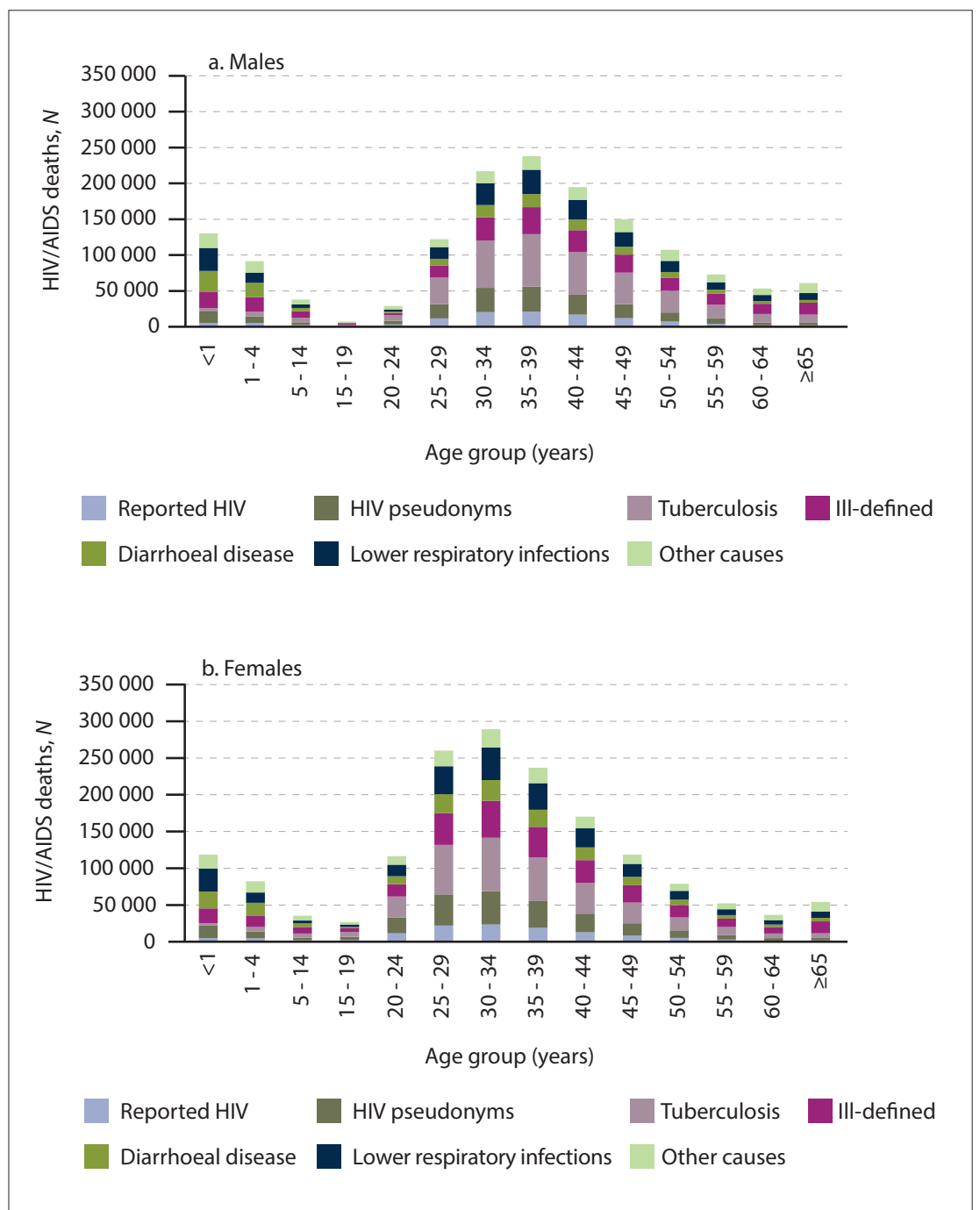

Figs $1 a$ and 1b. Estimated number of HIV/AIDS deaths by reported cause of death by sex and age for the period 1997 - 2012.

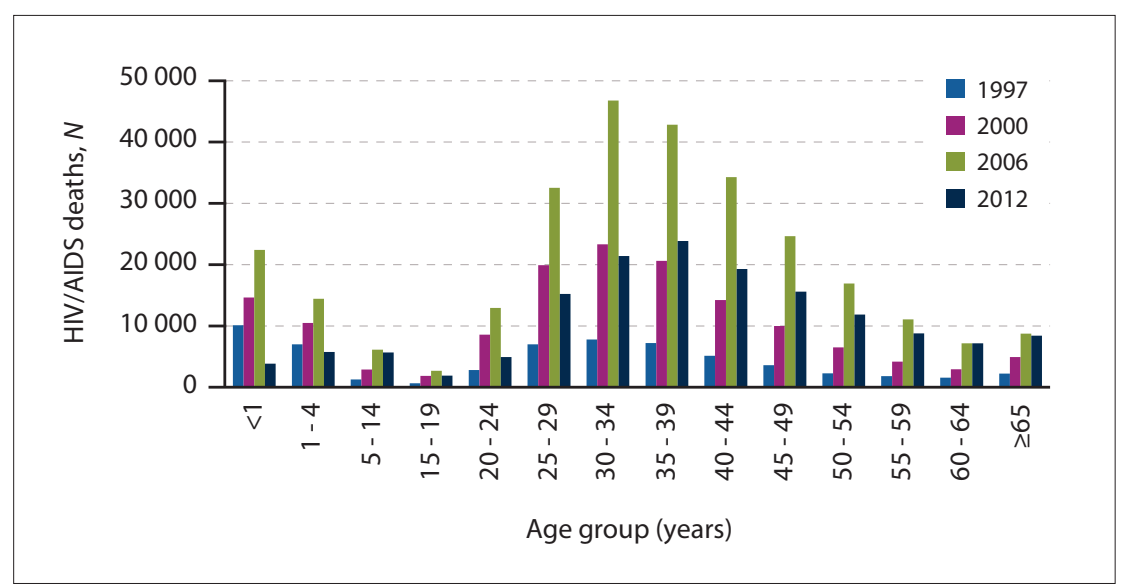

Fig. 2. Number of HIV/AIDS deaths by age group for 1997, 2000, 2006 and 2012.

reached levels of HIV/AIDS mortality rates similar or lower than those of 1997 (Fig. 4). KwaZulu-Natal experienced the highest HIV/ AIDS mortality rates throughout the period, followed (closely in the more recent years) by the Free State and then Mpumalanga. The 


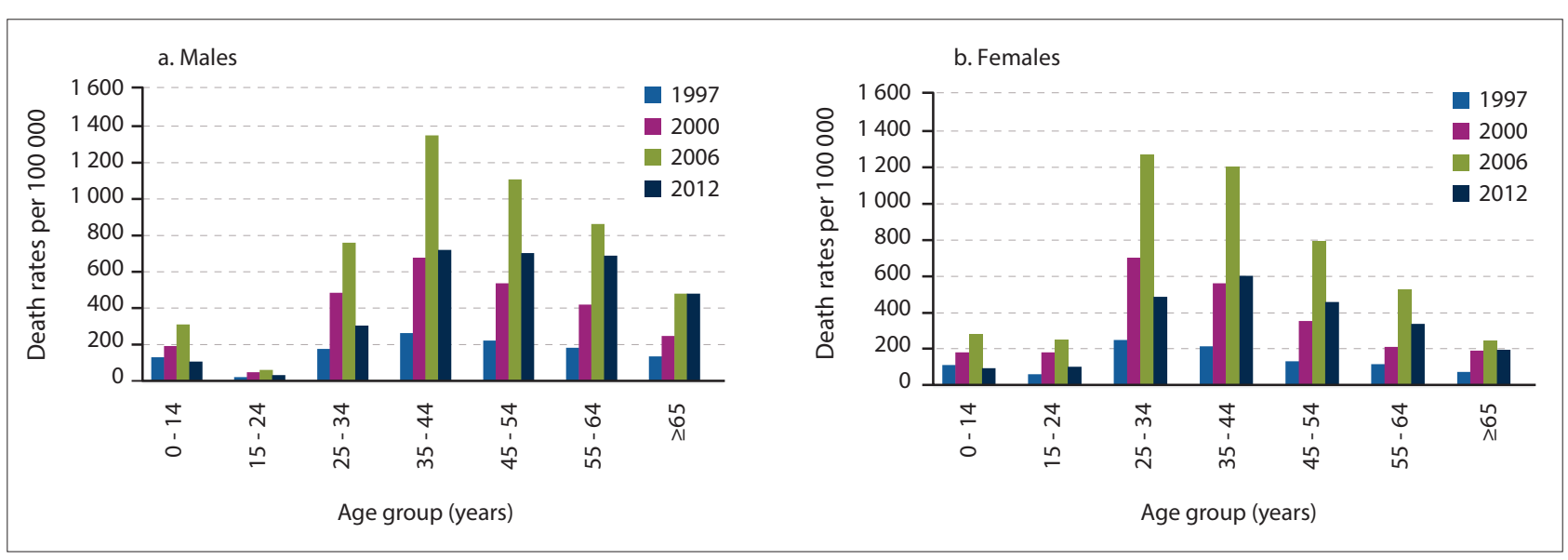

Figs 3a and 3b. HIV/AIDS mortality rates by sex and age group for 1997, 2000, 2006 and 2012.

Western Cape (WC), which consistently had the lowest HIV/AIDS mortality compared with other provinces, showed an increase until 2003 and little change in HIV/AIDS mortality thereafter; this differs from the characteristic HIV/AIDS trend in the rates of the other provinces, with the exception of Northern Cape (NC).

\section{Discussion}

Our study estimates that over three million HIV/AIDS deaths occurred between 1997 and 2012 and shows that, even though there have been gains in the battle against the HIV/AIDS epidemic in SA, by 2012 the country had yet to reach mortality levels experienced in 1997 (the earliest measure of the national number of HIV/AIDS deaths in the country from registered deaths). That said, Dorrington et al..$^{[18]}$ estimated some HIV/AIDS deaths in 1992/1993 from their projections using the ASSA600 AIDS and Demographic model. HIV/AIDS was still the leading cause of death in SA by 2012, even though the number of HIV/AIDS deaths had almost halved since the rollout of ART. ${ }^{[13]}$

SA's biggest success against the HIV/AIDS epidemic was among children under age 5 , where the number of deaths under age 1 was a third of those reported in 1997, and those aged 1 - 4 years were less in 2012 than in 1997. This reduction was due to the provision of ART to women, which reduced the transmission of HIV from mother to child. ${ }^{[19]}$

The finding that rates for men $\geq 45$ years did not decline much with age in 2012, and the rate for men $\geq 65$ years having not decreased since 2006, is a concern. The gap between rates of men and women increased in 2012, with the rate for men being 1.5 times higher than that for women in the 45 - 54-year age group, 2 times higher in the 55 - 64-year age group, and 2.5 times higher in the $\geq 65$ years age group. This male-female mortality differential and the challenge of high mortality among older men has been shown by Cornell et al. ${ }^{[20]}$ in a local study and was attributed to men entering the ART programme at an older age with an advanced stage of disease. Cornell et al. ${ }^{[20]}$ also reported that more women than men entered the ART programme in their small area study. The Joint United Nations Programme on HIV/AIDS (UNAIDS) has recognised that HIV response activities need to also focus on men, and launched the UNAIDS Platform for Action on men and $\mathrm{HIV}^{[21]}$ at the International AIDS Conference held in SA in July 2016. They identified that gender inequalities and harmful gender norms are important drivers of the HIV epidemic, which also negatively affects HIV response activities. Furthermore, UNAIDS reports that 'while access to HIV services for women and girls remains a concern, a growing body of evidence also shows that men and adolescent boys have limited access to HIV services and that

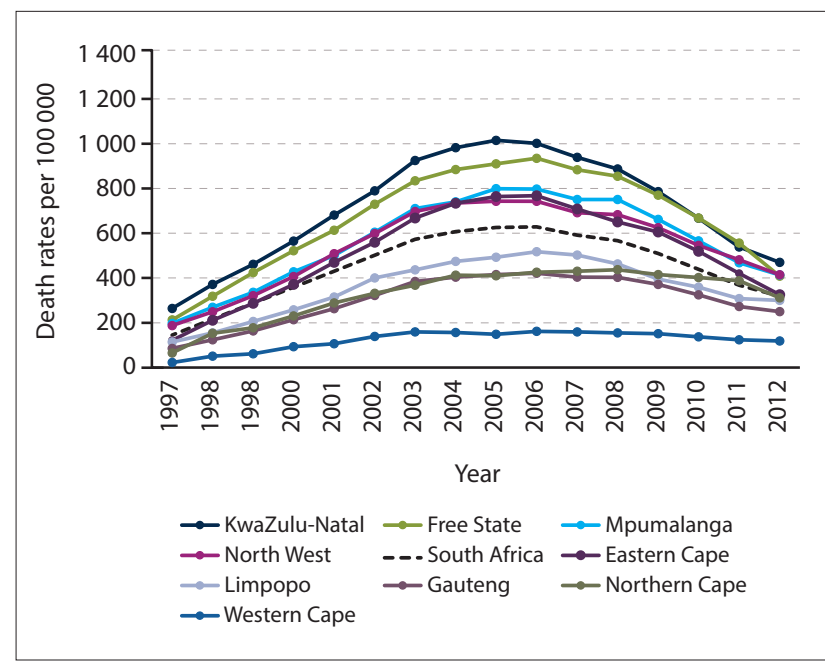

Fig. 4. Provincial and national HIV/AIDS mortality rates for the period $1997-2012$.

men are significantly underrepresented in HIV testing and treatment and similarly overrepresented in AIDS morbidity and mortality.'22]

Our provincial findings reveal that HIV/AIDS mortality decreased in all provinces since 2005/2006, soon after the intensified rollout of the ART programme in 2004. However, by 2012 none of the provinces had reached 1997 levels of mortality. The WC had low levels of HIV/AIDS mortality, which is in keeping with this province having the lowest prevalence of HIV. ${ }^{[23]}$ The levelling of WC mortality rates from 2003 may reflect the province's early response to the epidemic through the provision of treatment in demonstration projects at government clinics in 2001 and the early scale-up through primary care facilities in $2004{ }^{[24]}$ The continued increase in HIV/AIDS mortality up to 2008 in NC could be indicative of a slower response to the ART rollout driven by the widespread and sparse distribution of the population in this province.

Over $90 \%$ of identified HIV/AIDS deaths were misattributed to other conditions, with most of these coming from TB. This tendency is partly due to the reluctance of doctors to certify HIV/AIDS as a cause of death owing to stigma but also the fact that not all decedents had been tested for HIV, particularly in the early period. ${ }^{[10]}$ Efforts have been made to address this challenge; for example, the SAMRC, Stats SA and the National Department of Health conducted training for doctors on medical certification of cause of death in 2012, where it was clarified that if HIV is present, it should be indicated on the medical certificate completed by the doctor. This issue remains a 
challenge, and further training of doctors in medical certification is required.

More needs to be done to integrate health services to ensure treatment and care for HIV-positive patients with comorbidities. Routine testing for HIV as part of the health services is also needed for early diagnosis of HIV-positive individuals presenting with other conditions.

The National Burden of Disease Study assumes that there is a single underlying cause of death for each decedent. The consequence is to underplay the contribution of opportunistic infections, particularly $\mathrm{TB}$, because individuals with comorbid HIV have been attributed to HIV/AIDS.

In conclusion, even though SA is recognised as a success story in the fight against the HIV/AIDS epidemic, the country has not yet reached levels of HIV/AIDS mortality similar to 1997 - this is 12 years after an intense and extensive ART programme rollout. SA may have won many of the battles against HIV/AIDS, but the war is not over in all 9 provinces. In the past, HIV response activities targeted women and children in SA; however, our study - that revealed a surprising lack of improvement in mortality among older men - and others have shown that efforts also need to focus on getting men to initiate ART earlier with less advanced AIDS-related complications. Many have noted that men display poor health-seeking behaviour; however, the impact this has had on the HIV testing and treatment cascade needs attention. ${ }^{[25]}$ Mills et al. ${ }^{[26]}$ noted that 'Efforts to understand men's health-seeking behavior are poorly understood in the AIDS epidemic and encouraging men to get tested and into treatment is a major challenge, but one that is poorly recognized?. Tackling the challenge of formulating an appropriate HIV response for men is the next step for SA, and these activities must include adolescent boys and young men to encourage behaviours that promote better future healthseeking behaviours among men. Furthermore, more focus on the integration of health services to treat and care for HIV patients with comorbidities and implementing routine testing of patients for HIV as part of standard care will contribute to turning the tide against HIV/AIDS.

Author contributions. VPVW conceptualised the paper and wrote the first draft. RED and WM led the development of the methodology. WM led the programming and modelling. All authors contributed to the interpretation and writing of the paper.

Acknowledgement. Thanks to Ms Rifqah Roomaney for creating the bibliography.
Funding. This research was partly funded by the South African Medical Research Council's Flagships Awards Project (SAMRC-RFA-IFSP-01-2013/ SA CRA 2).

Conflicts of interest. None

1. UNAIDS. South Africa. https://www.unaids.org/en/regionscountries/countries/southafrica. (accessed 9 July 2019)

2. Johnson LF. Access to antiretroviral treatment in South Africa, 2004 - 2011. S Afr J HIV Med 2012:13(1):2227. https://doi.org/10.4102/sajhivmed.v13i1.156

3. Shisana O, Rehle T, Simbayi LC, et al. South African national HIV prevalence, incidence and behaviour urvey, 2012. Cape Town: HSRC Press, 2014

4. Shisana O, Rehle T, Simbayi LC, et al. South African national HIV prevalence, incidence behaviour and communication survey 2008: A turning tide among teenagers? Cape Town: HSRC Press, 2009

5. Shisana O, Rehle T, Simbayi L, et al. South African national HIV prevalence, HIV incidence, behaviour and communication survey, 2005. Report No. 0796921520. Cape Town: HSRC Press, 2005.

6. Shisana O, Simbayi L. Nelson Mandela HSRC Study of HIV/AIDS: Full report. South African national HIV prevalence, behavioral risks and mass media. Household survey 2002. Cape Town: HSRC Press, 2002.

7. Johnson L, Dorrington R. THEMBISA version 4.2: A model for evaluating the impact of HIV/AIDS in South Africa. Cape Town: University of Cape Town; 2019. https://www.thembisa.org/content/filedl/ Thembisa4_2report (accessed 9 July 2019).

8. Johnson L, Dorrington R. Modelling the impact of HIV in South Africass provinces: 2019 update. Cape Town: Centre for Infectious Disease Epidemiology and Research, University of Cape Town, 2019.

9. Statistics South Africa. Mortality and causes of death in South Africa, 2016: Findings from death notification. Pretoria: Stats SA, 2018. www.statssa.gov.za/publications/P03093/P030932016.pdf (accessed 9 July 2019).

10. Groenewald P, Nannan N, Bourne D, Laubscher R, Bradshaw D. Identifying deaths from AIDS in South Africa. AIDS 2005;19(2):193-201. https://doi.org/10.1097/00002030-200501280-00012

11. Statistics South Africa. Mortality and Causes of Death in South Africa, 2012: Findings from Death Notification. Pretoria: Statistics South Africa, 2014. http://www.statssa.gov.za/publications/P03093/ P030932012.pdf (accessed 9 July 2019).

12. Bradshaw D, Msemburi W, Dorrington R, Pillay-van Wyk V, Laubscher R, Groenewald P. HIV/AIDS in South Africa: How many people died from the disease between 1997 and 2010? AIDS 2016;30(5):771-778. https://doi.org/10.1097/gad.0000000000000947

13. Pillay-van Wyk V, Msemburi W, Laubscher R, et al. Mortality trends and differentials in South Africa from Pillay-van Wyk V, Msemburi W, Laubscher R, et al. Mortality trends and differentials in South Africa from (log) 2012 . Second National Burden of Dis

14. Stover $\mathrm{I}$, Andreev K, Slaymaker E, et al. Updates to the spectrum model to estimate key HIV indicators for 4. Stover J, Andreev K, Slaymaker E, et al. Updates to the spectrum model to estimate key HIV indicator
adults and children. AIDS 2014;28(4):S427-S434. https://doi.org/10.1097/qad.0000000000000483

adults and children. AIDS 2014;28(4):S427-S434. https://doi.org/10.1097/qad.0000000000000483
15. Pillay-van Wyk V, Laubscher R, Msemburi W, et al. Second South African National Burden of Disease S. Pillay-van Wyk V, Laubscher R, Msemburi W, et al. Second South African National Burden of Disease
Study: Data Cleaning, Validation and SA NBD List: South African Medical Research Council, 2014. http:// Study: Data Cleaning, Validation and SA NBD List: South African Medical Research Council, 214
www.mrc.ac.za/sites/default/files/files/2016-07-04/SANBDReport.pdf (accessed 9 July 2019).

www.mrc.ac.za/sites/default/files/files/2016-07-04/SANBDReport.pdf (accessed 9 July 2019).
16. Dorrington R. Alternative South African mid-year estimates, 2013. Cape Town: Centre for Actuarial 16. Dorrington R. Alternative South African mid-year estimates, 2013. Cape Town: Centre for Actuarial
Research, University of Cape Town, 2013. https://www.commerce.uct.ac.za/Research_Units/CARE/ Monographs/Monographs/Mono13.pdf (accessed 9 July 2019).

17. Ahmad OB, Boschi-Pinto C, Lopez AD, Murray CJ, Lozano R, Inoue M. Age standardization of rates: A new WHO standard. Geneva: WHO, 2001;9(10). https://www.who.int/healthinfo/paper31.pdf (accessed 9 July 2019).

18. Dorrington R, Bourne D, Bradshaw D, Laubscher R, Timæus IM. The impact of HIV/AIDS on adult mortality in South Africa: Technical Report. Cape Town: South African Medical Research Council, 2001. http://www.mrc.ac.za/sites/default/files/files/2017-05-26/complete.pdf (accessed 9 July 2019).

19. Ndirangu J, Newell ML, Thorne C, Bland R. Treating HIV-infected mothers reduces under 5 years of age mortality rates to levels seen in children of HIV-uninfected mothers in rural South Africa. Antivir Ther 2012;17(1):81-90. https://doi.org/10.3851/imp1991

20. Cornell M, Myer L, Kaplan R, Bekker L-G, Wood R. The impact of gender and income on survival and retention in a South African antiretroviral therapy programme. Trop Med Int Health 2009;14(7):722-731. https://doi.org/10.1111/j.1365-3156.2009.02290.x

21. UNAIDS. UNAIDS Platform for Action on Men and HIV. http://menengage.org/unaids-platform-foraction-on-men-and-hiv/ (accessed 9 July 2019).

22. UNAIDS. Male engagement in the HIV response - a Platform for Action. Geneva: UNAIDS, 2016 https:// www.ippforg/sites/default/files/2016-07/Male\%20Engagement $\% 20$ in $\% 20$ HIV\%20 response $\% 20-\% 20$ A\%20Platform $\% 20$ of $\% 20$ Action pdf (accessed 9 July 2019).

23. Johnson LE Dorrington RE Moolla H. HIV epidemic drivers in South Africa: A model-based evaluation Jofson LF, Dorrington RE, Moolla H. HIV epidemic drivers in South Africa: A model-based evaluation of factors accounting for inter-provincial differences in HIV prevalence and incidence trends. S Afr J HIV
Med 2017;18(1). https://doi.org/10.4102/sajhivmed.v18i1.695

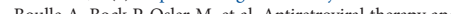

Boulle A, Bock P, Osler M, et al. Antiretroviral therapy and early mortality in South Africa. Bull World ealth Organ 2008;86:678-687.https://doi.org/10.247//BLT.07.045294

5. Huerga H, Van Cutsem G, Ben Farhat J, et al. Who needs to be targeted for HIV testing and treatment in KwaZulu-Natal? Results from a population-based survey. J Acquir Immune Defic Syndr 2016;73(4):4110001081

6. Mills EJ, Beyrer C, Birungi J, Dybul MR. Engaging men in prevention and care for HIV/AIDS in Africa. PLoS Med 2012;9(2):e1001167. https://doi.org/10.1371/journal.pmed.1001 